\title{
Travel Rates of Wolves, Canis lupus, in Relation to Ungulate Kill Sites in Westcentral Alberta
}

\author{
Gerald W. KuZYK ${ }^{1,2}$, Christoph Rohner ${ }^{1}$, and Fiona K. A. Schmiegelow ${ }^{1}$ \\ ${ }^{1}$ Department of Renewable Resources, University of Alberta, Edmonton, Alberta T9H 4N1 Canada \\ ${ }^{2}$ Corresponding author: gkuzyk@ualberta.ca
}

Kuzyk, Gerald W., Christoph Rohner, and Fiona K. A. Schmiegelow. 2005. Travel rates of Wolves, Canis lupus, in relation to ungulate kill sites in westcentral Alberta. Canadian Field-Naturalist 119(4): 573-577.

Recent advancements in Global Positioning Systems (GPS) radiocollar technology permit analysis of fine-scale animal movements. We used concurrent aerial and GPS monitoring to determine winter travel rates of Wolves (Canis lupus) in relation to ungulate kill sites in managed forest landscapes in westcentral Alberta. Wolves preyed predominately on Moose (Alces alces) and travelled 4.2 times less when near ungulate kill sites than when away from them. As Wolves are thought to be an important factor in Woodland Caribou (Rangifer tarandus caribou) declines, information is needed to assess predation risk to Caribou from Wolves under a variety of landscape conditions. If Wolves have restricted movements near Moose kill sites, this may lead to decreased encounter rates with Caribou in systems where Moose are abundant. Deer (Odocoileus spp.) are probably an important component of this Wolf-prey system but little is currently known about this relationship. Projecting long-term implications of ongoing development activities requires a more detailed understanding of the responses of all species to landscape change.

Key Words: Moose, Alces alces, Wolf, Canis lupus, predation risk, Woodland Caribou, Rangifer tarandus caribou, GPS data, Alberta.

Wolves (Canis lupus) travel extensively to locate prey (Mech 1970). For example, when hunting Moose (Alces alces), Wolves may travel 30-50 kilometres per day (Mech 1966; Peterson 1977; Mech et al. 1998). Woodland Caribou (Rangifer tarandus caribou) are classed as threatened in Alberta (Edmonds 1998; Dzus 2001) and Wolf predation is thought to be a major contributor to Caribou declines (Bergerud 1974; Edmonds 1988; Hayes et al. 2003). It is hypothesized that Woodland Caribou spatially separate themselves from Moose to avoid predation by Wolves (Bergerud and Elliot 1986; Seip 1992). Wolves may alter their use of habitats in response to industrial development such as forest harvesting (Kuzyk et al. 2004) and human infrastructure such as roads and trails can enhance Wolf movements (Formozov 1946; Thurber et al. 1994; Ciucci et al. 2003). James (1999) reported that Wolves in winter travelled 2.8 times faster on a linear corridor than in the forest. Such enhanced mobility has implications for search efficiency and encounter rates of Wolves with prey species. Increased information on Wolf-prey systems is essential for future Caribou conservation decisions (Hayes et al. 2003). Understanding Wolf travel rates in relation to ungulate kill sites offers one method of assessing predation risk to other prey species.

When Wolves kill large prey such as Moose, they usually spend two to four days near the carcass (Peterson 1977; Ballard et al. 1987; Mech et al. 1998; Hayes et al. 2000) whereas White-tailed Deer (Odocoileus virginianus) carcasses are generally handled in less than one day (Fuller 1989). After feeding on an ungulate carcass, Wolves may travel several kilometres to rest in open sunny areas, where digestion may be optimized (Mech 1970). During one study, Wolves were found near Moose kills in 21 of 31 days of continuous monitoring (Mech 1966), but fine scale movements near the carcasses were not recorded.

Observational studies of Wolves provide useful insight into Wolf hunting behaviour (Carbyn and Trottier 1988; Mech 1997) but there is little quantitative information on Wolf movements near kill sites, due to the technical difficulties of collecting such information (Mech 1995). Wolves have traditionally been studied using daily aircraft flights to relocate radiocollared Wolf packs, but this technique is limited by daylight and favourable weather (Mech 1995).

The objective of this study was to combine Global Positioning Systems (GPS) radio-collar technology with concurrent aerial observations to provide detailed information on Wolf travel rates in relation to ungulate kill sites. Wolves feeding on Moose are predicted to restrict movements when near carcasses (Mech 1966; Mech 1970) which should, theoretically, lessen predation risk to Caribou in systems where moose are abundant. Wolf packs feeding on deer should spend minimal time at kill sites (Fuller 1989), and more time travelling, which could result in increased predation risk to Caribou through random encounters.

\section{Study Area}

The study area is located in the foothills of west-central Alberta, near the town of Grande Cache $\left(54^{\circ} \mathrm{N}\right.$ $\left.119^{\circ} \mathrm{W}\right)$. The area is classed into subalpine and boreal natural subregions (Beckingham and Archibald 1996), and contains several main rivers and a dendritic pattern of creeks; lakes are scarce. Elevations range from 13001800 metres, and the climate is subarctic, with short wet summers and long cold winters. Temperatures aver- 
age $16^{\circ} \mathrm{C}$ in July and $-13.5^{\circ} \mathrm{C}$ in December (Beckingham and Archibald 1996). The forests are primarily Lodgepole Pine (Pinus contorta) and some White Spruce (Picea glauca). The wetland complexes support mostly Black Spruce (Picea mariana) and some Tamarack (Larix laricina). Some south facing slopes support Trembling Aspen (Populus tremuloides) and willow (Salix sp.).

This area supports a high diversity of large mammals: Woodland Caribou, Moose, Elk (Cervus elaphus), White-tailed Deer, Mule Deer (Odocoileus heminous), Bighorn Sheep (Ovis canadensis), Mountain Goats (Oreamnos americanus) and wild Horses (Equus cabalus). Wolves, Coyotes (C. latrans), Grizzly Bears (Ursus arctos), Black Bears (Ursus americanus) and Cougars (Felis concolor) also exist throughout the study area.

Major land use activities include forest harvesting, oil and gas exploration and development, coal mining, commercial trapping, and public uses such as hunting, fishing, hiking, horse packing and camping. Access is primarily on roads created for resource extraction, pipelines and seismic lines. Further descriptions of the study area can be found in Smith et al. (2000).

\section{Wolf captures and radio-tracking}

In January 2000, three Wolves from different packs (Simonette, Cutbank and Prairie Creek) were captured and immobilized by helicopter darting (Ballard et al. 1991) or netgunning (Kuzyk 2002) and instrumented with GPS radiocollars (Lotek Engineering Sytems, Newmarket, Ontario). All Wolf handling was approved by the University of Alberta's Faculty of Agriculture, Forestry and Home Economics Animal Care Policy (Number 96-99D), subject to the protocols of the Canadian Council of Animal Welfare. GPS collars were programmed to take one location per hour.

During a short period of intensive sampling, from 215 March 2000, these radiocollared Wolves and their associated pack members were followed by radiotracking from an airplane (Mech 1974). Wolves were relocated twice daily in hopes of detecting Wolf-killed deer (Fuller 1989). When a Wolf pack was located, the Wolves were counted and the area searched for ungulate carcasses. If an ungulate kill or most Wolf pack members were not immediately found, Wolf trails were backtracked until an ungulate carcass was found (Hayes et al. 2000).

\section{Wolf kill sites}

An ungulate kill was assumed to be caused by Wolves if there was evidence of bloodstained snow, a disarticulated carcass and Wolf trails indicating a successful chase (Hayes et al. 2000). Wolves were assumed to be scavenging if the carcass was on its sternum (Ballard et al. 1987) or human sign indicated the ungulate had been shot or road-killed. A GPS location was taken from an aircraft when directly over the kill site, with an estimated error of 73-128 metres (Carrel et al.
1997). Kill sites were visited twice daily until the Wolves abandoned the carcass. Wolves were classified as being near a kill when all or most members of the pack were seen within one kilometre of the new kill site.

Dead Moose were classified from the air as adult or calf (Peterson 1977). The amount of meat removed from the carcass was estimated (Carbyn 1983) and the number and behaviour of Wolves were recorded. All Wolf-killed ungulates for which species, sex and age (adult-calf) could not be confirmed from an airplane, and all others that were easily accessible with a helicopter, were later ground-inspected.

\section{Data analysis}

GPS location data were differentially corrected using N4Win Version 2.40, which reduced location error to 4-5 metres (Rempel and Rodgers 1997). Median travel distances in metres per one-hour interval $(\mathrm{m} / \mathrm{hr})$ were classified as kill site or non-kill site by calibrating the GPS data with field observation data. This was achieved by establishing a median time between each aerial observation in which Wolves were either near or away from an ungulate kill site. For example, if a Wolf pack was observed travelling at $1800 \mathrm{hr}$ in the evening, and then relocated near a recent ungulate kill at $0800 \mathrm{hr}$ the following morning (a time of 14 hours), the travel distances in the first seven-hour period were placed in the non-kill site category. Those distances in the remaining seven hour period were placed in the kill site category. While both calculation of straight-line distances between remotely-collected locations and proportional assignment of time intervals to behaviour categories can introduce errors in absolute representation of patterns, associated errors were consistent across all data collected. Further, because we were interested in relative patterns, rather than absolute measures, we do not feel these limitations unduly compromise our results.

All data were tested for normality before analysis and non-parametric procedures were used. All analyses were completed using SYSTAT (Version 8.0, SPSS Inc. 1998). To determine if travel distances differed when Wolves were near or away from ungulate kill sites, the GPS locations from the collared Wolves were pooled and classified into two categories: at or away from an ungulate kill site. A Mann-Whitney $U$-test was used to test for differences in travel distance between these two categories. To examine variation in travel rates among wolf packs, location data for each pack were similarly divided into two categories (kill site/non-kill site), and analysed separately using Mann-Whitney $U$-tests.

\section{Results}

The three Wolf packs were located at seven ungulate kill sites from 2-15 March 2000 (Table 1). The Simonette Wolf pack made multiple kills at two sites: a cow and calf Moose were killed within 500 metres of each other on or near the same day, and the scattered remains of two deer kills were found within 100 metres of each 
TABLE 1. Ungulate kill sites of three Wolf packs during 2-15 March 2000 in west-central Alberta.

\begin{tabular}{lcccc}
\hline \hline Wolf Pack and Size $(\mathrm{n})$ & Adult Moose & Calf Moose & Adult Elk & Deer \\
\hline Cutbank $(\mathrm{n}=8)$ & 1 & 1 & 0 & 0 \\
Prairie Creek $(\mathrm{n}=5)$ & 0 & 0 & 1 & 0 \\
Simonette $(\mathrm{n}=11)$ & $3^{*}$ & 0 & 0 & $1^{* *}$ \\
Totals & 4 & 1 & 1 & 1 \\
\hline \hline
\end{tabular}

* includes one multiple kill of 1 cow and 1 calf Moose which is considered 1 kill

** includes one multiple kill of 2 deer which is considered 1 kill

TABLE 2. Wolf travel distances $(\mathrm{m} / \mathrm{hr}$ ) at and away from seven ungulate kill sites as determined by one-hour GPS locations from three Wolves in separate packs during 2-15 March 2000 in west-central Alberta.

\begin{tabular}{lccc}
\hline \hline & $\begin{array}{c}\text { All Travel } \\
(\mathrm{m} / \mathrm{hr})\end{array}$ & $\begin{array}{c}\text { Travel at Kill } \\
(\mathrm{m} / \mathrm{hr})\end{array}$ & $\begin{array}{c}\text { Travel Away from Kill } \\
(\mathrm{m} / \mathrm{hr})\end{array}$ \\
\hline Number of cases & 553 & 288 & 265 \\
Minimum & 0.2 & 0.2 & 0 \\
Maximum & 6100 & 2044 & 6100 \\
Standard Deviation & 749 & 326 & 963 \\
Median* & 80 & 45 & 190
\end{tabular}

*(Mann-Whitney $U$ test $P \leq 0.001$ )

other (Table 1). To be conservative, multiple kills were pooled for analysis.

Wolves travelled a median distance of $80 \mathrm{~m} / \mathrm{hr}$ during 14 consecutive days of monitoring (Table 2). They moved a median distance of $45 \mathrm{~m} / \mathrm{hr}$ when near ungulate kill sites, which differed significantly from a median distance of $190 \mathrm{~m} / \mathrm{hr}$ per hour when they were not near kill sites $(U=26362, P \leq 0.001)$.

Patterns in travel distance varied among Wolf packs. The Cutbank Wolf pack, which was only observed on Moose kills during the monitoring period, showed a highly significant difference $(U=1667, P \leq 0.001)$ in travel distances when at or away from kill sites. The Simonette pack, which was found near both Moose and deer kills, showed a marginally significant difference ( $U=2740, P=0.067)$ between travel distances at and away from kill sites. During aerial monitoring, only one Elk kill was recorded for the Prairie Creek pack and no difference $(U=2702, P=0.601)$ in travel distances related to kill sites was detected (Table 3 ).

\section{Discussion}

In this study, GPS radiocollar technology allowed Wolf travel rates to be recorded on a continuous (hourly) basis, irrespective of daylight and weather, and account- ed for associated feeding, resting and other social behaviours. Further, by combining GPS radio-collar technology with traditional methods used to study wolf kill rates (Mech 1974), a more comprehensive representation of wolf travel rates was established. Results from this approach found a clear difference in Wolf travel rates related to ungulate kill sites, which is consistent with both anecdotal information and other research (Mech 1966; Peterson 1977; Hayes et al. 2000).

We found that Wolves travelled a median distance of $0.08 \mathrm{~km} / \mathrm{hr}$, which is substantially lower than that reported for Wolves travelling in the forest during winter (1.6-6.1 km/hr) (Musiani et al. 1998), on iced surfaces $(8 \mathrm{~km} / \mathrm{hr})($ Mech 1966), and on tundra during summer $(8.7 \mathrm{~km} / \mathrm{hr})$ (Mech 1994). This difference could be largely due to the advantages of continuous (hourly) GPS monitoring in this study. While the data-collecting period seldom lasted more than a few hours in other studies, due to the requirement for maintenance of visual or auditory contact with the Wolves (Musani et al. 1998; Mech 1994), GPS technology provides for continuous data collection. As such, it provides information on movement patterns of Wolves that includes time spent in a variety of behaviours, such as resting, and stopping at old kill sites.

TABLE 3. A comparison of median Wolf travel distances $(\mathrm{m} / \mathrm{hr})$ at and away from ungulate kill sites $(\mathrm{n}=$ number of GPS locations) for three Wolves in separate packs during 2-15 March 2000 in west-central Alberta.

\begin{tabular}{lccc}
\hline \hline Wolf Pack & $\begin{array}{c}\text { Travel at Kill } \\
(\mathrm{m} / \mathrm{hr})\end{array}$ & $\begin{array}{c}\text { Travel Away from Kill } \\
(\mathrm{m} / \mathrm{hr})\end{array}$ & $\begin{array}{c}\text { Mann-Whitney } \\
U \text { test }(P)\end{array}$ \\
\hline Cutbank & $37(\mathrm{n}=135)$ & $148 \quad(\mathrm{n}=48) \leq$ & $\leq 0.001$ \\
Prairie Creek & $357 \quad(\mathrm{n}=36)$ & $338 \quad(\mathrm{n}=159)$ & 0.601 \\
Simonette & $37(\mathrm{n}=116)$ & $57 \quad(\mathrm{n}=57)$ & 0.067 \\
\hline \hline
\end{tabular}


However, these results are also lower than those reported by James (1999) for a boreal region of Alberta, where GPS collared Wolves moved $0.5 \mathrm{~km} / \mathrm{hr}$ in the forest and averaged $1.4 \mathrm{~km} / \mathrm{hr}$ on linear corridors. James (1999) collected GPS locations every five minutes with the objective of establishing Wolf speed, whereas in this study the collars obtained hourly locations with the purpose of establishing coarser estimates of Wolf travel distances in relation to kill sites. Frequency of locations can influence estimation of travel rates due to the linear extrapolation required between time intervals. In addition, the boreal region of Alberta has less topographic relief than the foothills of west-central Alberta, which could also account for some difference in Wolf travel rates. Finally, prey type and density, as well as pack and territory size could also influence movement patterns and resultant estimates of travel rates. Further investigation of these differences is warranted in order to better understand regional patterns.

The travel rate of Wolves in relation to ungulate kill sites provides important information when assessing predation risk to Caribou. Wolf travel distances were 4.2 less when near kill sites $(45 \mathrm{~m} / \mathrm{hr})$ than when away from kill sites $(190 \mathrm{~m} / \mathrm{hr})$. We suggest that differences in travel patterns between the three Wolf packs studied were likely due to the different prey species each pack was hunting. The Cutbank pack showed the greatest differences in travel at and away from kill sites and was found only at Moose kills. In one case, the pack remained near a cow Moose carcass for longer than four days, which reduced overall travel during the sampling interval.

The Simonette Wolf pack travelled marginally shorter distances when at, compared with away from ungulate kills. Their travel near kills was, in fact, the same as the Cutbank pack, but they travelled much less when away from kill sites. This result may be due to a combination of an overall high kill rate of ungulates (Kuzyk 2002) and partial consumption of prey (Carbyn 1983). As well, this Wolf pack made multiple kills of ungulates (e.g., Ballard et al. 1987; Mech et al. 1998) which would reduce their overall travel.

The Prairie Creek pack showed no difference in travel related to ungulate kills, with only one Elk kill being documented during aerial monitoring. This Wolf pack contained the fewest members $(n=5)$ during the study and pack size can affect ungulate kill rates (Fuller 1989; Schmidt and Mech 1997; Hayes et al. 2000). Nevertheless, it also likely that the Prairie Creek pack was preying on deer, as these Wolves were observed hunting deer on a number of occasions, although no deer kills were found (see also Carbyn 1974). Fuller (1989) discusses in detail the logistical problems of determining Wolf kill rates of deer, due to the short time frame in which Wolves handle deer carcasses and the difficulty in detecting Wolf-killed deer from the air. If deer are the main prey for the Prairie Creek pack, then Caribou may face greater predation risk in this territory, than in the territories of packs preying primarily on Moose, due to associated increases in travel and encounter rates. The extensive, recent logging in the area (Smith et al. 2000) could favour deer numbers, and thereby influence predation risk to Caribou. Wolves in this study area were found to use forest cutblocks proportionately more than unharvested forests, which may be a response to increased number of deer and other ungulates that are attracted to the young vegetation in the cutblocks (Kuzyk et al. 2004). A greater understanding of the role of deer in this Wolf-prey system is required, as most of the forest in westcentral Alberta has been allocated for timber harvest.

Projecting the long-term implications of ongoing development activities for Wolf-prey systems requires a more detailed understanding of the responses of all species to landscape change (Bergerud 1974), and both the functional and numerical response of Wolves to changes in ungulate prey abundance and distribution at relevant spatial scales (see Lessard 2005). The results of this study provide information on movement patterns of Wolves in relation to ungulate kills, which could be expanded by calibrating the more extensive GPS-database with signals detected from concurrent aerial observations (Franke 2004). This would result in a larger sample of potential kill sites for further analysis of predation patterns in relation to landscape features.

\section{Acknowledgments}

Funding for this research was provided by the WestCentral Alberta Caribou Standing Committee, the Alberta Sport, Recreation, Parks and Wildlife Foundation, and a University of Alberta Challenge Grant in Biodiversity (supported by the Alberta Conservation Association). A University of Alberta Graduate Research Assistantship and the Margaret Brown Award in Environmental Studies and Wildlife Resources provided financial assistance to G. Kuzyk. We acknowledge the safe piloting conducted by Clay Wilson from Bighorn Helicopters and Denny Dennison from Coyote Air during wolf captures and monitoring.

\section{Literature Cited}

Ballard, W. B., J. S. Whitman, and C. L. Gardner. 1987. Ecology of an exploited wolf population in south-central Alaska. Wildlife Monographs 114: 1-49.

Ballard, W. B., L. A. Ayres, K. E. Roney, and T. H. Spraker. 1991. Immobilization of gray wolves with a combination of tiletamine hydrochloride and zolazepam hydrocloride. Journal of Wildlife Management 55: 71-74.

Beckingham, J. D., and J. H. Archibald. 1996. Field guide to the ecosites of west-central Alberta. Canadian Forest Service, Northwest Region, Northern Forestry Center, Edmonton, Alberta.

Bergerud, A. T. 1974. Decline of caribou in North America following settlement. Journal of Wildlife Management 38: 757-770. 
Bergerud, A. T., and J. Elliot. 1986. Dynamics of caribou and wolves in northern British Columbia. Canadian Journal of Zoology 64: 1515-1529.

Carbyn, L. N. 1974. Wolf predation and behavioral interactions with elk and other ungulates in an area of high prey diversity. Canadian Wildlife Service Report, Edmonton, Alberta.

Carbyn, L. N. 1983. Wolf predation on elk in Riding Mountain National Park, Manitoba. Journal of Wildlife Management 47: 963-976.

Carbyn, L. N., and T. Trottier. 1988. Descriptions of wolf attacks on bison calves in Wood Buffalo National Park. Arctic 41: 297-302.

Carrel, W. K., R. A. Ockenfels, J. A. Wennerlund and J. C. Devos. 1997. Topographic mapping, LORAN-C, and GPS accuracy for aerial telemetry locations. Journal of Wildlife Management 61: 1406-1412.

Ciucci, P., M. Masi, and L. Boitani. 2003. Winter habitat and travel route selection by wolves in the northern Apennines, Italy. Ecography 26: 223-235.

Dzus, E. 2001. Status of woodland caribou (Rangifer tarandus caribou) in Alberta. Environment, Fisheries and Wildlife Management Division, and Alberta Conservation Association, Wildlife Status Report Number 30, Edmonton, Alberta, Canada.

Edmonds, E. J. 1988. Population status, distribution and movements of woodland caribou in west central Alberta. Canadian Journal of Zoology 66: 817-826.

Edmonds, E. J. 1998. Status of woodland caribou in Alberta. Rangifer Special Issue Number 8: 111-115.

Formozov, A. N. 1946. Snow cover as an integral factor of the environment and its importance in the ecology of mammals and birds. Moscow Society of Naturalists, Moscow, USSR. English translation 1969. Boreal Institute, University of Alberta, Edmonton, Alberta, Occasional Publication: 1-141.

Franke, K. A. 2004. Analysis of space-time action systems in woodland caribou (Rangifer tarandus) using Hidden Markov Models. Ph.D. dissertation, University of Alberta, Edmonton. 105 pages.

Fuller, T. K. 1989. Population dynamics of wolves in northcentral Minnesota. Wildlife Monographs 105: 1-41.

Hayes R. D., A. M. Baer, U. Wotschikowsky, and A. S. Harestad. 2000. Kill rate by wolves on moose in the Yukon. Canadian Journal of Zoology 78: 49-59.

Hayes, R. D., R. S. Farnell, R. M. P. Ward, J. Carey, M. M. Dehn, G. W. Kuzyk, A. M. Baer, C. L. Gardner, and M. O'Donoghue. 2003. Experimental reduction of wolves in the Yukon: ungulate responses and management implications. Wildlife Monographs: 152: 1-35.

James, A. R. C. 1999. Effects of industrial development on the predator-prey relationship between wolves and caribou in northeastern Alberta. Ph.D. dissertation, University of Alberta, Edmonton. 70 pages.

Kuzyk, G. W. 2002. Wolf distribution and movements on caribou ranges in west-central Alberta. M.Sc. thesis. University of Alberta, Edmonton, Alberta. 125 pages.

Kuzyk, G. W., J. Kneteman, and F. K. A. Schmiegelow. 2004. Winter habitat use by Wolves, Canis lupus, in relation to forest harvesting in west-central Alberta. Canadian Field-Naturalist 118: 327-334.
Lessard, R. B. 2005. Conservation of woodland caribou (Rangifer tarandus caribou) in west-central Alberta: a simulation analysis of multi-species predator-prey systems. Ph.D. thesis. University of Alberta, Edmonton, Alberta. 188 pages.

Mech, L. D. 1966. The wolves of Isle Royale. U.S. National Park Fauna Series Number 7.

Mech, L. D. 1970. The wolf: ecology and behavior of an endangered species. Natural History Press, Doubleday Publishing Co., New York.

Mech, L. D. 1974. Current techniques in the study of elusive wilderness carnivores. Pages 315-322 in Proceedings of the International Union of Game Biologists. Edited by I. Kjerner and P. Bjurholm. Swedish National Environment Protection Board, Stockholm, Sweden.

Mech, L. D. 1994. Regular and homeward travel speeds of arctic wolves. Journal of Mammalogy 75: 741-742.

Mech, L. D. 1995. What do we know about wolves and what more do we need to learn? Pages 537-545 in Ecology and conservation of wolves in a changing world. Edited by L. N. Carbyn, S. H. Fritts and D. R. Seip. Canadian Circumpolar Institute, Occasional Publication Number 35, University of Alberta, Edmonton, Alberta, Canada.

Mech, L. D. 1997. The Arctic Wolf - Ten years with the pack. Raincoast Books Publishing, Vancouver, British Columbia, Canada.

Mech, L. D., L. G. Adams, T. J. Meier, J. W. Burch, and B. W. Dale. 1998. The Wolves of Denali. University of Minnesota Press.

Musiani, M., H. Okarma, and W. Jedrzejewski. 1998. Speed and actual distances traveled by radiocollared wolves in Bialowieza Primeval Forest (Poland). Acta Theriologica 43: 409-416.

Peterson, R. O. 1977. Wolf ecology and prey relationships on Isle Royale. United States National Park Series Science Monograph, Number 11.

Rempel, R. S., and A. R. Rodgers. 1997. Effects of differential correction on accuracy of a GPS animal location system. Journal of Wildlife Management 61: 525-530.

Schmidt, P. A., and L. D. Mech. 1997. Wolf pack size and food acquisition. The American Naturalist 150: 513-517.

Seip, D. R. 1992. Factors limiting woodland caribou populations and their relationships with wolves and moose in southeastern British Columbia. Canadian Journal of Zoology 70: 1494-1503.

Smith, K. G., E. J. Ficht, D. Hobson, T. C. Sorensen, and D. Hervieux. 2000. Winter distribution of woodland caribou in relation to clear-cut logging in west-central Alberta. Canadian Journal of Zoology 78: 1433-1440.

Thurber, J. M.., R. O. Peterson, T. D. Drummer, and S. A. Thomasa. 1994. Gray wolf response to refuge boundaries and roads in Alaska. Wildlife Society Bulletin 22: 61-68.

Received 4 February 2005

Accepted 14 December 2005

Added in proof

Franke, A., T. Caelli, G. Kuzyk, and R. J. Hudson. 2006. Prediction of wolf (Canus lupus) kill-sites using hidden Markov models. Ecological Modeling 197: 237-246. 